\title{
LETTER TO THE EDITOR Eruptive Pseudoangiomatosis in a Child Undergoing Chemotherapy for Hodgkin Lymphoma
}

To the Editor: Eruptive pseudoangiomatosis (EP) was originally described in 1969 by Cherry et al. [1] as hemangioma-like lesions in four children who had echovirus infections. In 1993, the name "eruptive pseudoangiomatosis" was coined. The lesions are characterized as red angioma-like eruptions, usually on the limbs and cheeks, which appear suddenly and resolve within 2 weeks. In children, this entity has been associated with viral etiology [2,3].

A 13-year-old Caucasian male, while undergoing the second cycle of chemotherapy for stage IV-B Hodgkin lymphoma with doxorubicin, bleomycin, vincristine, etoposide, cyclophosphamide, and prednisone per COG AHOD0932 protocol, presented with approximately ten new-onset skin lesions. There was no history of recent fevers, sore throat, cough, diarrhea or lymphadenopathy or history of affected family members. They were located on both arms and one on the cheek, appearing as bright, angiomalike and blanching papules surrounded by a halo (Fig. 1A,B). He

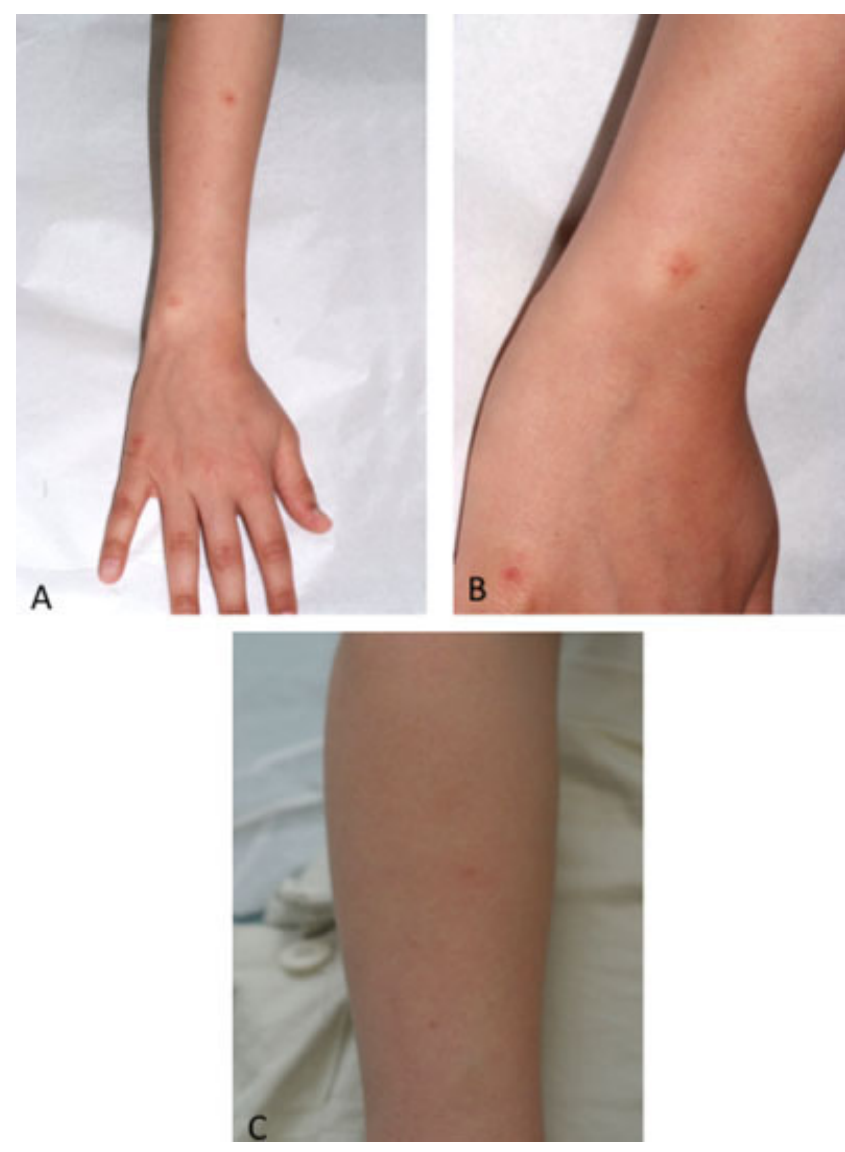

Fig. 1. Eruptive pseudoangiomatosis lesions at initial presentation (A) and (B). Lesions, nearly resolved, after 2 months (C). was diagnosed with EP. Differential diagnosis included bacillary angiomatosis and spider telangiectasias. Testing for Bartonella was negative at that time. Within 4 weeks, the lesions began to fade, and 2 months later, they were barely visible (Fig. 1C). His chemotherapy was completed and there has been no recurrence of EP or Hodgkin lymphoma in the last 1 year.

EP is a benign, self-limited dermatosis, originally described in children [4], and, more recently, in adults [5,6]. In some cases, it has been linked to viruses and insect bites [7], and even reported to have occurred as an outbreak in one Italian community [8]. In both children and adults it appears as a dermatosis involving both the limbs and the face, of small, angioma-like papules with a surrounding halo that blanches with pressure. Dilated dermal blood vessels with plump endothelial cells without increased number of blood vessels and a perivascular lymphocytic infiltrate are seen on histology.

In children, EP has been associated with a viral prodrome, and in adults with immune compromise [9], and in one report, cytomegalovirus [10]. This case illustrates the unique circumstance of an immunocompromised pediatric patient developing the dermatosis. Furthermore, the rash was not preceded by prodromal symptoms. This case is similar to an episode in an adult renal transplant recipient [11] where, despite ongoing immune compromise secondary to chemotherapy, the rash resolved. Resolution of the dermatosis and lack of relapse re-emphasize the self-limited nature of the condition even in immunocompromised individuals.

Meret Henry, MD Carman and Ann Adams Department of Pediatrics Division of Hematology/Oncology Children's Hospital of Michigan Wayne State University School of Medicine Detroit, Michigan

Süreyya Savaşan, MD Carman and Ann Adams Department of Pediatrics Division of Hematology/Oncology Pediatric Blood and Marrow Transplant Program Children's Hospital of Michigan Barbara Ann Karmanos Cancer Center Wayne State University School of Medicine Detroit, Michigan
*Correspondence to: Süreyya Savaşan, MD, Children's Hospital of Michigan, Division of Hematology/Oncology, 3901 Beaubien Blvd, Detroit, MI 48201. E-mail: ssavasan@med.wayne.edu

Received 20 October 2011; Accepted 21 November 2011

(C) 2011 Wiley Periodicals, Inc. 


\section{References}

1. Cherry JD, Bobinski JE, Horvath FL, et al. Acute hemangioma-like lesions associated with ECHO viral infections. Pediatrics 1969;44:498-502.

2. Neri I, Patrizi A, Guerrini V, et al. Eruptive pseudoangiomatosis. Br J Dermatol 2000;143:435-438.

3. Larralde M, Ballona R, Correa N, et al. Eruptive pseudoangiomatosis. Pediatr Dermatol 2002;19:76-77.

4. Angelo C, Provini A, Ferranti G, et al. Eruptive pseudoangiomatosis. Pediatr Dermatol 2002;19:243245 .

5. Yang JH, Kim JW, Park HS, et al. Eruptive pseudoangiomatosis. J Dermatol 2006;33:873-876.

6. Guillot B, Dandurand M. Eruptive pseudoangiomatosis arising in adulthood: 9 cases. Eur J Dermatol 2000;10:455-458.
7. Restano L, Cavalli R, Colonna C, et al. Eruptive pseudoangiomatosis caused by an insect bite. J Am Acad Dermatol 2005;52:174-175.

8. Venturi C, Zendri E, Medici MC, et al. Eruptive pseudoangiomatosis in adults: A community outbreak. Arch Dermatol 2004;140:757-758

9. Chaniotakis I, Nomikos K, Gamvroulia C, et al. Eruptive pseudoangiomatosis: Report of an adult case and unifying hypothesis of the pathogenesis of paediatric and adult cases. Dermatology 2007;215: $59-62$

10. Pitarch G, Torrijos A Garcia-Escriva D, et al. Eruptive pseudoangiomatosis associated to cytomegalovirus infection. Eur J Dermatol 2007;17:455-456.

11. Mazereeuw-Hautier J, Cambon L, Bonafe JL. Eruptive pseudoangiomatosis in an adult renal transplant recipient. Ann Dermatol Venereol 2001;128:55-56. 